\title{
CDC Grand Rounds: Adolescence - Preparing for Lifelong Health and Wellness
}

\author{
Stephen Banspach, $\mathrm{PhD}^{1}$; Stephanie Zaza, MD${ }^{1}$; Patricia Dittus, $\mathrm{PhD}^{2}$; Shannon Michael, $\mathrm{PhD}^{3}$; Claire D. Brindis, DrPH ${ }^{4}$; Phoebe Thorpe, MD
}

Approximately 42 million adolescents aged 10-19 years, representing $13 \%$ of the population, resided in the United States in 2014 (1). Adolescence is characterized by rapid and profound physical, intellectual, emotional, and psychological changes (2), as well as development of healthy or risky behaviors that can last a lifetime. Parents have strong influence on their adolescent children's lives, and family-based programs can help parents support healthy adolescent development. Because schools are natural learning environments, implementing and improving school-based policies and programs are strategic ways to reinforce healthy behaviors and educate adolescents about reducing risky behaviors. Health care during adolescence should be tailored to meet the changing developmental needs of the adolescent while providing welcoming, safe, and confidential care. Parents, educators, care providers, public health officials, and communities should collaborate in fostering healthy environments for all adolescents, now and into the future.

Although adolescence is usually a relatively healthy life stage, preventable causes of death, illness, and injury do occur. Unintentional injuries (3), followed by suicide and homicide, are the top three causes of death among adolescents (Figure). Injuries are also the leading cause of nonfatal morbidity among adolescents (Table). During 2013, approximately 4 million unintentional nonfatal injuries resulted from being struck by something, falling, overexertion, car crashes, and other mechanisms. In addition, approximately 260,000 youths were treated in emergency departments for nonfatal physical assault injuries (excluding sexual assault), and $8 \%$ of high school students attempted suicide. Birthrates continue to decrease among teens, but during 2013, approximately 273,000 births to mothers aged 15-19 years occurred (4). Chlamydia and gonorrhea are prevalent among both males and females aged 15-19 years, and $25 \%$ of all reported chlamydia and gonorrhea infections occur in this age group (5).

Health outcomes often are driven by health risk behaviors established during adolescence. Preventing initiation

This is another in a series of occasional MMWR reports titled CDC Grand Rounds. These reports are based on grand rounds presentations at CDC on high-profile issues in public health science, practice, and policy. Information about CDC Grand Rounds is available at http://www.cdc.gov/cdcgrandrounds. of potentially harmful behaviors (e.g., smoking and binge drinking) and encouraging healthy eating and physical activity during adolescence can have lifelong health benefits. During $2013,88 \%$ of students in grades $9-12$ rarely or never used bicycle helmets; $41 \%$ texted or sent e-mails while driving a car; and a quarter were involved in physical fights (6). Sedentary behavior continues to be a challenge among adolescents, with only $27 \%$ getting the recommended 60 minutes of daily physical activity (6). Television-watching and other types of screen time are common, with $41 \%$ of students using computers and other devices for nonschool-work. In addition, recommendations for healthy eating (e.g., eating fruits and vegetables) are infrequently followed (7). Risk behaviors also contribute to negative reproductive health outcomes. Approximately half of high school students are sexually active, but few use the most effective contraceptives. Approximately $41 \%$ do not use condoms, leaving substantial numbers of teens unprotected against pregnancy and sexually transmitted diseases. Finally, substance use, which is prevalent among adolescents, contributes to both short- and long-term health risks. One third of high school students currently use alcohol, 23\% use marijuana, and 22\% use all forms of tobacco combined (G).

Public health's role in understanding and addressing adolescent health should provide adolescents with effective, accurate, and developmentally appropriate health promotion and disease prevention education and comprehensive health services. Such efforts require strategies and approaches that engage adolescents in the settings where they live, learn, and receive health care.

\section{Family-Based Approaches}

Family-based approaches aim to maximize the positive influence that parenting behaviors have on children by building parents' knowledge, skills, and confidence in communicating about risk, providing adequate monitoring and supervision, modeling positive behaviors, and building strong, trusting relationships with their children. Research has demonstrated that family-based interventions can reduce risk behaviors and improve health outcomes across multiple areas, including sexual initiation, delinquent behavior, and alcohol, tobacco, and drug use (8). Important components of effective familybased interventions include parenting skill-building activities with opportunities for improvement through practice (e.g., with other parents in a workshop or with their adolescent child 
FIGURE. Proportional distribution of leading causes of death* among adolescents aged 10-19 years — United States, 2014

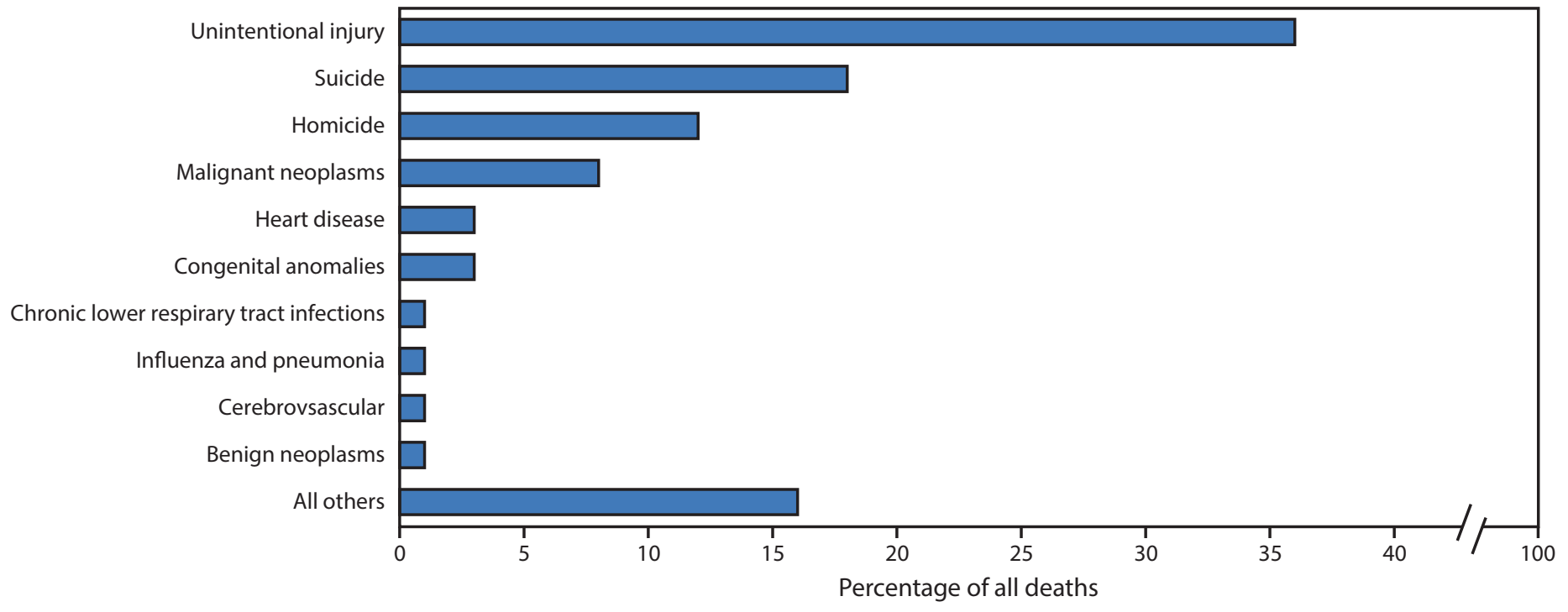

Source: CDC. Web-based Inquiry Statistics Query and Reporting System (WISQARS). http://webappa.cdc.gov/sasweb/ncipc/leadcaus10_us.html.

* Unintentional injuries include motor vehicle/traffic (2,834; 63\%), poisoning (589; 13\%), drowning (350; 8\%), and other $(713 ; 16 \%)$.

TABLE. Nonfatal health outcomes among adolescents aged 10-19 years - United States, 2013-2014*

\begin{tabular}{|c|c|c|}
\hline Indicator & $\begin{array}{c}\text { Age group } \\
\text { or grade range }\end{array}$ & $\begin{array}{l}\text { Estimate } \\
\text { (no. or \%) }\end{array}$ \\
\hline Unintentional injuries ${ }^{\dagger}$ & $10-19$ yrs & $4,373,717$ \\
\hline Physical assault injuries $^{\dagger}$ & $10-19 y r s$ & 260,949 \\
\hline Suicide attempt ${ }^{\S}$ & 9 th-12th grade & $8 \%$ \\
\hline Teen pregnancy & $15-19 \mathrm{yrs}$ & 273,000 \\
\hline Chlamydia** & $15-19$ yrs & 381,717 \\
\hline Gonorrhea** & $15-19$ yrs & 68,468 \\
\hline Asthma ${ }^{\dagger \dagger}$ & $0-17$ yrs & $9 \%$ \\
\hline Obese $(\mathrm{BMI} \geq 95 \text { th\%) })^{\S \S}$ & $12-19$ yrs & $21 \%$ \\
\hline
\end{tabular}

Abbreviation: $\mathrm{BMI}=$ body mass index.

* Nonfatal outcome data for 2013 includes injuries, suicide, and pregnancy. Nonfatal outcome data for 2014 includes sexually transmitted infections, asthma, and obesity.

† CDC. Web-based Inquiry Statistics Query and Reporting System. Atlanta, GA: U.S. Department of Health and Human Services, CDC; Nonfatal Injuries 2013, United States, All Races, Both Sexes, Ages 10 to 19. http://webappa.cdc.gov/ sasweb/ncipc/nfirates2001.html.

$\S$ Kann L, Kinchen S, Shanklin S, et al. Youth risk behavior surveillance-United States, 2013. MMWR 2014;63(No. SS-4). https://www.cdc.gov/mmwr/preview/ mmwrhtml/ss6304a1.htm.

I CDC. Vital Signs: preventing teen pregnancy. Atlanta, GA: U.S. Department of Health and Human Services; 2015. http://www.cdc.gov/vitalsigns/larc/ index.html.

** CDC. Sexually transmitted disease surveillance 2014. Atlanta, GA: U.S. Department of Health and Human Services, CDC; 2015. https://www.cdc. gov/std/stats14/surv-2014-print.pdf.

t† CDC. National Health Interview Survey U.S. Atlanta, GA: U.S. Department of Health and Human Services, CDC; 2014 https://www.cdc.gov/asthma/ nhis/2014/table4-1.html.

$\S \S$ CDC. National Health and Nutrition Examination Survey, 2013-2014. Atlanta, GA: U.S. Department of Health and Human Services, CDC; [undated]. http:// wwwn.cdc.gov/nchs/nhanes/search/nhanes13_14.aspx. through joint homework assignments) and follow-up during brief sessions or telephone calls. During the follow-up interactions, parents are provided opportunities for feedback on attempted changes and additional information and guidance.

Despite the availability of these interventions, parents often face challenges participating in family-based programs because of busy schedules and competing demands, which can result in an inability to attend by those parents who could most benefit from the programs. Successful programs are those that include flexible scheduling and additional support through meals, transportation, and child care, all of which increase the likelihood that busy parents will attend. Alternate settings for workshops (e.g., workplaces or clinics) can help facilitate parents' participation $(9,10)$. To date, few family-based interventions are brief programs that can reach large numbers of participants while demonstrating impact on adolescent behaviors. Programs that can overcome these barriers warrant further development and evaluation.

\section{School-Based Approaches}

Approximately 37,000 U.S. middle and high schools serve 38 million adolescents. Schools can provide opportunities for adolescents to learn about and practice healthy behaviors that can improve their health now and lead to continued healthy outcomes and success in the future. Healthy students are better learners (11) and have higher academic achievement and high school graduation rates, which translate to lifelong health benefits (12), underscoring the shared interest in promoting adolescent health among education 
and health leaders. Schools can serve as principal venues for health education, health promotion, and disease prevention in ways that are supported by research. Schools are ideal places for conducting standards-based health education that sets expectations for what students should know and be able to do by grades 2, 5, 8, and 12 to promote personal, family, and community health (13); providing quality physical education and promoting physical activity and nutrition throughout the school environment $(14,15)$; implementing comprehensive risk reduction interventions (16); providing cost-effective access to school-based health services (17); and implementing school policies and programs designed to create environments that are safe, positive, and supportive of healthy behaviors $(18,19)$. To accomplish these goals, schools need a holistic approach to addressing students' health and learning. This includes having a coordinated approach that includes developing, implementing, and evaluating school policies and practices; creating supportive and safe school environments; improving the school nutrition environment and nutrition services; having comprehensive school physical activity programs with physical education as the foundation; implementing quality health education; serving students' physical and mental health and social service needs; partnering with families and the community; and promoting schoolwide healthy environments through school personnel wellness programs and health-related professional development opportunities for school employees (15).

Schools are places designed for learning, including learning about health. However, schools often face challenges in being the location for health promotion and disease prevention activities. Provision of health and physical education is often constrained by limitations in scheduling or the availability of qualified teachers. Traditional school practices regarding foods available in vending machines or other sources (e.g., à la carte) might conflict with recommendations for healthy eating. Health services are frequently limited by insufficient resources for school nursing and health care programs. CDC has developed a tool, the School Health Index (http://www. cdc.gov/HealthyYouth/SHI/), to assist educators and parents to improve school health programs. The index helps school health committees assess strengths and weaknesses across different health topics (e.g., physical education and physical activity, nutrition, tobacco use prevention, asthma care, unintentional injury and violence prevention, and sexual health), and take steps to improve school health policies and programs.

\section{Health Services}

Adolescence is a time when youths become increasingly responsible for their own health care as part of their growing independence and transition into adulthood. Because adolescent health problems are largely preventable, primary care visits offer an opportunity to provide evidence-based effective services (e.g., education, preventive screenings, and treatment) (20). Annual preventive care visits have been recommended for adolescents since the 1990s, although data indicate that fewer than half of adolescents have an annual well-care visit, with noted disparities attributable to insurance coverage, income, race/ethnicity, and sex (21). Overall, during 2011, $43 \%$ of adolescents had a preventive health visit. However, only $38 \%$ of adolescents living at or below the federal poverty level were likely to receive such services, and only a quarter of adolescents who lacked health insurance received a preventive visit. Important racial/ethnic disparities also existed, with only $37 \%$ of Hispanics receiving preventive health visits, whereas $43 \%$ of non-Hispanic blacks and $45 \%$ of non-Hispanic whites had received these visits (21). School-based health centers can provide an important avenue for reducing these disparities. School-based health centers in low-income communities have been demonstrated to improve both educational and health outcomes (22). Improved educational outcomes include school performance, grade promotion, and high school completion. Improved health outcomes include increased delivery of vaccinations and other recommended preventive services, increased contraceptive use among females, increased prenatal care, decreased asthma morbidity, and fewer emergency department visits and hospital admissions.

Regardless of where services are provided, opportunities for improving access to and use of clinical preventive services for adolescents include new coverage options provided by the Affordable Care Act $(23,24)$ and ensuring that health care services are youth-friendly and developmentally appropriate. Principles that should guide adolescent health services include ensuring 1 ) availability of quality programs and services; 2 ) availability of programs and services developmentally tailored to the needs of early, middle, and late adolescence; 3) accessibility (e.g., transportation and ease of use); 4) welcoming environments for adolescents; and 5) an atmosphere where adolescents' opinions and experiences are valued.

Two challenges to providing health services for adolescents are maintaining confidentiality of services (i.e., keeping private patients' personal health information that is disclosed to their health care provider) and understanding minor consent laws (i.e., laws that enable minors to give consent for certain health care services). Providers have limits on how and when patient information can be shared with others. Traditionally, they are able to share health information only under limited circumstances, particularly if the young person poses a risk to himself or herself or others. Concern also exists in situations where an explanation of benefits might be sent from an insurer to the primary policyholder, revealing the sensitive nature of a medical care visit (25). Minor consent laws vary considerably 
among states with regard to whether adolescents are able to give consent for selected sensitive health care services, including screening and treatment for sexually transmitted infections, mental health counseling, substance use services, and reproductive health services. Addressing these challenges to confidentiality and clarifying and communicating information about minor consent laws to adolescents, parents, schools, and health care providers are required to ensure that these barriers to adolescent health care are eliminated.

\section{Conclusion}

Adolescence is a period of intense growth and development. Supporting adolescents' health requires parents, schools, health care systems, and communities to help youths to be healthy throughout adolescence, develop healthy behaviors for a lifetime, and learn how to access and use the health care system. Parents, educators, and health care providers share the ultimate goal of helping adolescents achieve healthy, successful futures.

\footnotetext{
${ }^{1}$ Division of Adolescent and School Health, National Center for HIV/AIDS, Viral Hepatitis, STD, and TB Prevention, CDC; ${ }^{2}$ Division of STD Prevention, National Center for HIV/AIDS, Viral Hepatitis, STD, and TB Prevention, CDC; ${ }^{3}$ Division of Population Health, National Center for Chronic Disease Prevention and Health Promotion, CDC; ${ }^{4}$ Adolescent and Young Adult Health National Resource Center, University of California, San Francisco; ${ }^{5}$ Office of the Director, CDC.
}

Corresponding author: Stephen W. Banspach, SBanspach@cdc.gov, 404-718-8101.

\section{References}

1. US Census Bureau. Age and sex: 2014 American Community Survey 1-year estimates. Washington, DC: US Census Bureau; 2014. http:// factfinder.census.gov/faces/tableservices/jsf/pages/productview. xhtml?pid=ACS_12_1YR_S0101\&prodType=table

2. American Academy of Pediatrics. Stages of adolescence. Elk Grove Village, IL: American Academy of Pediatrics; 2015. https://www.healthychildren. org/English/ages-stages/teen/Pages/Stages-of-Adolescence.aspx

3. Sleet DA, Ballesteros MF, Borse NN. A review of unintentional injuries in adolescents. Annu Rev Public Health 2010;31:195-212. http://dx.doi. org/10.1146/annurev.publhealth.012809.103616

4. CDC. Vital signs: preventing teen pregnancy. Atlanta, GA: US Department of Health and Human Services, CDC; 2015. http://www. cdc.gov/vitalsigns/larc/index.html

5. CDC. Sexually transmitted disease surveillance 2014. Atlanta, GA: US Department of Health and Human Services, CDC; 2015. http://www. cdc.gov/std/stats14/surv-2014-print.pdf

6. Kann L, Kinchen S, Shanklin SL, et al. Youth risk behavior surveillanceUnited States, 2013. MMWR Suppl 2014;63(No. Suppl 4).

7. Kim SA, Moore LV, Galuska D, et al. Vital signs: fruit and vegetable intake among children-United States, 2003-2010. MMWR Morb Mortal Wkly Rep 2014;63:671-6.

8. Community Preventive Services Task Force. Improving adolescent health through interventions targeted to parents and other caregivers: a recommendation. Am J Prev Med 2012;42:327-8. http://dx.doi. org/10.1016/j.amepre.2011.11.009
9. Schuster MA, Corona R, Elliott MN, et al. Evaluation of Talking Parents, Healthy Teens, a new worksite based parenting programme to promote parent-adolescent communication about sexual health: randomised controlled trial. BMJ 2008;337:a308. http://dx.doi.org/10.1136/ bmj.39609.657581.25

10. Guilamo-Ramos V, Bouris A, Jaccard J, Gonzalez B, McCoy W, Aranda D. A parent-based intervention to reduce sexual risk behavior in early adolescence: building alliances between physicians, social workers, and parents. J Adolesc Health 2011;48:159-63. http://dx.doi. org/10.1016/j.jadohealth.2010.06.007

11. Basch CE. Healthier students are better learners: a missing link in school reforms to close the achievement gap. Equity matters: research review no. 6. New York, NY: Columbia University; 2010. http://www.equitycampaign. org/i/a/document/12557_EquityMattersVol6_Web03082010.pdf

12. Freudenberg N, Ruglis J. Reframing school dropout as a public health issue. Prev Chronic Dis 2007;4:A107. http://www.cdc.gov/pcd/ issues/2007/oct/07_0063.htm

13. The Joint Committee on National Health Education Standards. National health education standards: achieving excellence. 2nd ed. Atlanta, GA: American Cancer Society; 2007.

14. Task Force on Community Preventive Services. Recommendations to increase physical activity in communities. Am J Prev Med 2002;22(Suppl):67-72. http://dx.doi.org/10.1016/S0749-3797(02)00433-6

15. CDC. School health guidelines to promote healthy eating and physical activity. MMWR Recomm Rep 2011;60(No. RR-5).

16. Community Preventive Services Task Force. Recommendations for groupbased behavioral interventions to prevent adolescent pregnancy, human immunodeficiency virus, and other sexually transmitted infections: comprehensive risk reduction and abstinence education. Am J Prev Med 2012;42:304-7. http://dx.doi.org/10.1016/j.amepre.2011.11.006

17. Wang LY, Vernon-Smiley M, Gapinski MA, Desisto M, Maughan E, Sheetz A. Cost-benefit study of school nursing services. JAMA Pediatr 2014;168:642-8. http://dx.doi.org/10.1001/jamapediatrics.2013.5441

18. CDC. Results from the School Health Policies and Practices Study 2014. Atlanta, GA: US Department of Health and Human Services, CDC; 2015. http://www. cdc.gov/healthyyouth/data/shpps/pdf/shpps-508-final_101315.pdf

19. CDC. School connectedness: strategies for increasing protective factors among youth. Atlanta, GA: US Department of Health and Human Services, CDC; 2009. http://www.cdc.gov/healthyyouth/protective/pdf/connectedness.pdf

20. US Preventive Services Task Force. What is the task force and what does it do? Rockville, MD: US Preventive Services Task Force; 2016. http:// www.uspreventiveservicestaskforce.org/

21. Adams SH, Park MJ, Irwin CE Jr. Adolescent and young adult preventive care: comparing national survey rates. Am J Prev Med 2015;49:238-47. http://dx.doi.org/10.1016/j.amepre.2015.02.022

22. Community Preventive Services Task Force. Promoting health equity through education programs and policies: school-based health centers. Atlanta, GA: US Department of Health and Human Services, CDC; 2015. www. thecommunityguide.org/healthequity/education/schoolbasedhealthcenters.html

23. American Academy of Pediatrics (AAP). Health reform and the AAP: what the new law means for children and pediatricians. Elk Grove Village, IL: American Academy of Pediatrics; [undated]. https://www.aap.org/en-us/advocacy-andpolicy/federal-advocacy/Documents/ACAImplementationFactSheets.pdf

24. National Adolescent and Young Adult Health Information Center. The Affordable Care Act: implications for adolescents and young adults. San Francisco, CA: University of California; 2012. http://nahic.ucsf.edu/resources/aca/

25. Society for Adolescent Health and Medicine; American Academy of Pediatrics. Confidentiality protections for adolescents and young adults in the health care delivery and insurance claims process. J Adolesc Health 2016;58:374-7. http://dx.doi.org/10.1016/j.jadohealth.2015.12.009 